\title{
O filme e a representação do real
}

\author{
Cristiane Freitas Gutfreind ${ }^{1}$ \\ PUC-RS \\ cristianefreitas@pucrs.br
}

Resumo: Esse texto tem por objetivo tentar compreender as transformações por que vem passando a idéia de representação e a significação do real no cinema. Para isso, analisaremos o papel do documentário apresentado em diferentes suportes e formas de escrituras.

Palavras-Chave: cinema. real. representação.

Abstract: This text has like gif to understand changing of the idea of representation and the meaning of the real in the movies. In this way, we will analyze le function of documentary presented in different manners and forms of writing

Key-words: film. real. representation.

Resumé: Ce texte essaie de compreendre les tansformations dans l'idée de répresentation et la signification du réel dans le cinéma contemporain. On va analyser le rôle du documentaire presentés dans ses différents formes et écriture.

Mots-clés: cinéma. réel. répresentation.

Resumen: Este texto tiene como objetivo entender las transformaciones de la idea de la representación y la significação del real en el cine hoy. Para esto, analizaremos el papel del documentario presentados en diversas formas $y$ escritura.

Palabras-Llaves: cine.real. representación.

${ }^{1}$ Professora do Programa de Pós-Graduação em Comunicação Social da PUC-RS. 
Nesse texto, tentaremos construir uma reflexão de como, através das teorias de cinema, podemos compreender as mutações na idéia de representação, sobretudo pelo viés do real que encontrou, na atualidade, um lugar de expressão no documentário; esse por sua vez, renovou-se através de diferentes formatos e escrituras, alcançando uma importante presença nas salas de cinema.

Partindo do pressuposto de que "todo filme é um filme de ficção" (AUMONT, 1999, p.70), ou seja, o cinema tem o poder de transformar objetos, pessoas e narrativa em ausentes no tempo e no espaço, é possível pensar que todo filme de "ficção" ou "documental" representa o irreal no sentido de que aquilo que vemos na tela é justamente o ausente; dessa forma, tentaremos entender como esses dois tipos de filme se complementam na atualidade para construir a sua estética.

O cinema pode ser compreendido como uma estrutura plural que engloba produção, consumação, hábitos, criatividade, valores simbólicos e imaginários que dizem respeito a uma sociedade específica. Nesse sentido, um dos vários campos que compreende o estudo de cinema se interessa pela organização sociocultural da sua produção e pelo que a experiência fílmica aporta a uma sociedade específica; mais particularmente, podemos dizer que o cinema, como outras mídias, funciona como um produto de base da sociedade contemporânea, participando da psiquê da comunidade, da consciência e da experiência dos indivíduos.

Analisar, portanto, o cinema como objeto de comunicação relacional através da sua idéia de representação e construção da realidade, inserindo-se em uma rede midiática em plena ebulição de ordem econômica, estética, tecnológica, perceptiva e simbólica. Assistimos, assim, atualmente, a uma proliferação de novos tipos de imagens documentais que trazem a tona os estudos de cinema dedicados ao real.

Segundo diferentes abordagens teóricas, até os anos 60, a representação fílmica era entendida como tendo um papel de mediação permitindo que uma coisa que não estivesse presente em um determinado instante, ou seja, a realidade, pudesse se apresentar sob uma outra forma: em imagem. Podemos dizer, então, que a capacidade mimética dos filmes começou a ser pensada desde os anos 20 através de teorias de cinema. Podemos destacar aqui Rudolf Arnheim, entre outros, que tentou legitimar a vocação estética e viu no advento do cinema falado, da consolidação da 
indústria hollywoodiana e da implantação do sistema de gêneros uma maneira de arranhar a autonomia artística do filme. Porém, outras teorias foram desenvolvidas nos anos 40 e 50, sobretudo as concebidas por André Bazin e Siegfried Kracauer, que recusaram esse sistema de gêneros para defender um "cinema-olho", entendido como uma apreensão da experiência ou do real liberado das convenções estabelecidas. Essas últimas teorias foram elaboradas paralelamente às transformações do pósguerra, o que nos leva a constatar que, mesmo que elas tenham procurado associar a autonomia estética do cinema à representação da realidade, permitiram uma interação entre a teoria e a experiência fílmica baseada no momento histórico, fato que se concretizou, nos anos 6o, nos movimentos do Neo-Realismo e do Cinema Novo.

Foi também nos anos 60 que o cinema continuou a se interrogar sobre o específico fílmico, inserindo essa questão dentro de um contexto científico. A reflexão sobre a imagem cinematográfica se instalou sistematicamente dentro dos meios acadêmicos, sustentada pelas teorias da comunicação e da linguagem que se alastraram com vigor nessa década, junto com o desenvolvimento de uma reflexão sobre as mídias e a sociedade informatizada.

Nesse contexto próprio às ciências, que diz respeito a uma construção rigorosa dos objetos de estudo, encontramos a teoria de Christian Metz, que propôs fazer do cinema um objeto da semiologia. Com ele, o estudo do cinema torna-se um estudo da lingüística do cinema. Desde então, sobretudo nos anos 70 e 80, mesmo enfrentando vários impasses, os teóricos darão menos importância à especificidade fílmica para centralizar suas teorias em um dialogo com outras disciplinas. Essa orientação permitiu uma interação entre uma reflexão sobre o cinema e uma variedade de estudos, com efeitos que se fazem sentir até hoje, como a referência à psicanálise, a inserção do cinema no campo das teorias narrativas, a sociologia do cinema e a renovação do debate entre cinema e história.

Além dessas reflexões, encontramos em voga a teoria que estabelece uma relação entre o discurso filosófico e as imagens fímicas, referência direta à teoria elaborada por Gilles Deleuze, cuja abordagem do cinema apresenta uma constelação de conceitos visando a afirmar o status particular das imagens fílmicas como filosofia em ato; segundo ele, "o cinema é uma nova prática de imagens e de signos, cuja 
filosofia deve fazer a teoria como prática conceitual” (DELEUZE, 1985, p.366). Deleuze foi influenciado por Henri Bergson, Merleau-Ponty e Walter Benjamin, e todos desenvolveram teorias que relacionavam o cinema e a filosofia, porém cada uma delas tratava essa abordagem de modo diferenciado.

Foi assim que a idéia de representação adquiriu uma nova dimensão, estabelecendo mudanças definidas por Casetti como "a idéia de transparência se opõe a de opacidade" e "a idéia de funcionalidade opõem-se a de resistência"(CASETTI, 1999, p.229). A representação é, então, considerada como um meio de corporificar as aparências e dar forma ao espírito.

Especular a noção de representação nos remete ainda a Roland Barthes e a sua amplamente divulgada teoria do "terceiro sentido", segundo a qual poderemos distinguir três níveis na imagem fílmica: um nível "informativo", que nos remete a um tipo de conhecimento originário do cenário, dos personagens, do figurino, etc.; um nível simbólico que diz respeito aos símbolos ligados ao tema do filme, ao seu autor e a seu referencial e, ainda, um nível obtuso, da ordem do sensível e que nos leva à emoção, ao afetivo. A partir desses três níveis, Barthes tentou compreender as projeções elaboradas pelo espectador e o caráter duplo das imagens, permitindo-nos entender a representação em sua dimensão simbólica e afetiva.

Essa idéia também foi seguida por Jean-François Lyotard de uma maneira mais direta e menos detalhada em artigo só recentemente traduzido para o português. O texto refere-se à idéia de "acinema", que vem a ser a realização de imagens fílmicas daquilo que é irrepresentável, ou seja, a disjunção entre a realidade e o seu duplo em função da repressão de um em favor do outro. Para Lyotard, o cinema exclui as coisas irrepresentáveis na medida em que elas não são recorrentes. Por isso, podemos dizer que "representação" passa a ser uma "apresentação" no sentido de colocar em imagens as aparências ou aquilo que está em evidência.

Dessa forma, pensar sobre a representação nos remete à percepção de que as dimensões miméticas, funcionais e simbólicas são uma ilusão, pois não se trata apenas a conversão do ausente em presente, mas de uma tensão aberta, em termos do imaginário, entre um substituinte e um substituído, entre um resultado e o trabalho 
do qual ele é originário. Assim, a imagem fílmica é tida como fazendo parte de um conjunto em que aquilo que se percebe na tela é o seu duplo.

O debate sobre a representação se desenvolveu a partir da idéia de que a subjetividade das imagens está relacionada com a interação existente entre a complexidade do cinema e a sua técnica.

É a partir desse pressuposto que poderemos evocar a teoria desenvolvida por Jacques Aumont e Michel Marie no livro L'analyse des films (1988), onde fazem dialogar a psicanálise, a sociologia e a narratologia. Em suma, os autores destacam que o mundo visto nas telas, através dos filmes, é uma construção nascida da interação entre um produto constituído por condições materiais específicas, para as quais as salas de cinema determinam apenas uma pequena fatia da recepção e da existência, e a autonomia do filme como obra artística composta de recursos profílmicos (a cor, o enquadramento, a luz), que dão um significado específico e produzem um efeito particular sobre o espectador.

Foi assim que a reflexão sobre a representação colocou o cinema contemporâneo no centro de um amplo debate sobre o seu papel como arte autônoma presa a uma rede de comunicação midiática, marcada por diferentes tecnologias e novas formas de produção e suscitando abordagens subjetivas no espectador. É nesse sentido que, para o diretor Carlos Diegues, a representação cinematográfica funciona como uma "dialética onde a realidade se torna ficção e onde ao mesmo tempo a ficção se torna realidade".

Porém, compreender o cinema a partir dessa concepção reflexiva nos remete a uma teoria construída por Edgar Morin, nos anos 50, no livro O Cinema Ou O Homem Imaginário (1970), na qual o cinema é entendido como uma organização sociocultural que o organiza (aspecto não desenvolvido no livro pelo autor) e o imaginário. Ao contrário das teorias realistas elaboradas no mesmo período, sobretudo as concebidas por Kracauer e Bazin como vimos anteriormente, Morin define o cinema como uma máquina que registra a existência e a restitui como tal, porém levando em consideração o indivíduo, ou seja, o cinema seria um meio de transpor para a tela o universo pessoal, solicitando a participação do espectador. Assim, temos a dimensão subjetiva que faz nascer o imaginário. Essa dimensão se 
desenvolve em dois níveis: de um lado, essa subjetividade nos remete ao mundo vivido, fruto de uma elaboração mais ou menos pessoal e resultado da imaginação do criador, tornando-se perceptível na tela; daí o interesse pelo conteúdo do filme, apreendido por Morin como capaz de suscitar percepções relacionadas ao sonho; por outro lado, essa subjetividade caracteriza a relação estabelecida entre o espectador e o filme, sua compreensão de uma situação representada baseando-se nos seus conhecimentos, suas suposições e suas expectativas, disso decorre, o interesse pela estrutura da imagem fímica e por sua capacidade em despertar emoções.

Esse livro de Morin sofre uma grande influência das teorias desenvolvidas por André Bazin, que exalta a capacidade da fotografia de compreender diretamente o real. Já Morin insiste na dimensão de mediação entre a imagem e o homem, mas, da mesma forma que Bazin, Morin condiciona a realização de um filme ao contexto social, limitando, assim, a sua teoria ao fato de ter no real uma necessidade de suporte para o cinema.

Um exemplo concreto da força dessas teorias na contemporaneidade e das transformações na concepção da idéia de representação é a explosão do documentário como gênero cinematográfico no mundo todo. Hoje, o documentário não é mais considerado como pertencendo a um gueto, engessado em um gênero bem definido, cujo certificado de autenticidade se sustenta na verdade, de fato encontramos um conjunto de filmes em plena evolução sem necessariamente uma unidade ou uma definição e cuja inspiração continua sendo a realidade. A diversidade de formatos, que vai do antigo filme-reportagem, passando pela formatação televisiva e chegando ao digital, além de múltiplas maneiras de escrita, pode ser percebida em filmes como Entreatos (João Salles, 2004) ou Extremo Sul (Mônica Schmiedt e Sylvestre Campe, 2005), só para ficar na produção nacional, levando-nos a constatar uma pluralidade e um entusiasmo no processo criativo nos quais à ficção atual deixa a desejar. Isso se deve, ao fato de que o documentário resolveu reencontrar a sua essência sem se preocupar com uma crise identitária imposta desde sempre em comparação com a ficção; como afirma Emmanuel Burdeau, o documentário conseguiu "encontrar um lugar, através do efeito, ao incomparável"(BURDEAU, 2004, p.12), ou seja, sua característica de incomparável sustenta-se na diversidade 
que o documentário vem produzindo nos últimos tempos em termos de polêmica e atitudes no rastro da trilha traçada por Michael Moore.

Assim, a polêmica em torno do filme Ser e Ter (Etre et avoir, Nicolas Philibert, 2002)², sem levar em consideração qualquer tipo de julgamento moral, só confirma as transformações por que está passando o documentário na atualidade. Se, durante muito tempo, o cinema serviu como meio de veicular as existências íntimas e os gestos da História, hoje essa situação mudou, devido, especialmente, à grande penetração de câmeras na vida privada e o triunfo da tele-realidade como perversão do pacto documentário. Ou seja, o documentário se encontra, atualmente, no limiar entre o sucesso e o fracasso, pois, de um lado, o mundo disponível para ser captado por uma câmera não passa de um grande estúdio cheio de pessoas ávidas em mostrar a sua experiência pessoal para que essa lhe renda alguma celebridade, como nos reality shows, e, de outro lado, ainda é possível encontrar um mundo externo e intocável onde ainda é permitido aceder com uma câmera cinematográfica.

Diante desse impasse, o documentário usa estratégias para cativar o público, dando ao formato procedimentos do entretenimento (como podemos ver em Mondovino, Jonathan Nossiter, 2005) e, ao mesmo tempo, reformulando a sua estética. Nesse dilema interior e exterior, difundido pelos diferentes tipos de reality show, o documentário passa a se interessar também pelo pequeno mundo interior, físico e mental. Temos em Eduardo Coutinho o mais contundente representante nacional dessa prática, com obras como Santo Forte(1999), Babilônia 20oo(2001), Edifício Master(2004).

Podemos dizer, então, que os reality shows são apenas um filtro no sentido de que a realidade que transmitem é selecionada, e a mise en scène (roteiro, discurso,

\footnotetext{
${ }^{2}$ A polêmica em torno do filme começou em 2003, quando a história de um professor de uma escola infantil, localizada na região rural da França, tomou um rumo diferente da sua proposta inicial de um documentário dirigido a um pequeno público específico que, provavelmente, não sairia das fronteiras francesas. Como em toda obra cinematográfica, em que a atração do público pelo filme não consegue ser medida previamente, Ser e Ter acabou sendo exibido em várias partes do mundo, atraindo cada vez mais público, fato que rendeu ao seu diretor um reconhecimento inesperado. Por causa disso, o dedicado professor Lopez, o professor, figura central do filme, entrou com uma ação contra o realizador exigindo direitos autorais, pois ele alegava ter sido dirigido como qualquer outro personagem de ficção. $\mathrm{O}$ imbróglio se arrastou na justiça, onde, até o momento, Lopez perdeu em todas as instâncias, levantando no meio cinematográfico francês um debate sobre a questão de como as câmeras devem se portar frente ao privado em tempos de reality show.
} 
cenário e decupagem) é precisamente determinada de forma que todos os participantes obedeçam a um único modo de ser, já pré-estabelecido. Portanto, se constitui em um universo sem narrativa, determinado pela duração contínua de um acontecimento, onde a informação é reduzida a um enunciado de fatos, e a principal questão colocada pela direção é como encontrar uma figuração. Já o documentário junta os planos sem a pretensão de anular o sujeito a um personagem, mas sim de trabalhar a desconstrução do sujeito como instância unificada e estruturante.

É assim que o documentário vai estreitando cada vez mais seus laços com a televisão, colocando-se no centro de sua programação, por vezes como meio de difusão privilegiada, sobretudo nos canais fechados e buscando, através desse meio, um maior alcance do público. Ao mesmo tempo, nos últimos anos, os documentários alcançaram um aumento expressivo dos filmes em salas em praticamente todo o mundo. Isso se deve, basicamente, a perda de entusiasmo e desconfiança do público pela ficção; esse tipo de cinema padronizado criou um imaginário em que o espectador deve se identificar com o personagem, tornando-se até mesmo a sua consciência. Porém, os filmes sensíveis à realidade, preocupam-se em articular menos o olhar do público, mostrando mais a existência pelo viés da ausência, como Um Especialista (Un spécialiste, portrait d'un criminel moderne, Eyal Sivan, 1999).

Dessa maneira, a linguagem ficcional não conseguiu se renovar esteticamente e acompanhar as mudanças tecnológicas, principalmente aquelas que entendem o cinema contemporâneo como fazendo parte de uma rede multiforme de imagens e sons, ao contrário, do que aconteceu com o documentário que, ao diversificar sua linguagem, reforçou o seu diálogo com a televisão. Além disso, a reportagem propagada pela televisão sofreu cada vez mais um descrédito do público, fazendo com que o documentário assumisse por vezes o papel de legitimador da informação, o que pode ser visto em filmes como Notícias de Uma Guerra Particular (João Salles, 1999) ou Ônibus 174 (José Padilha, 2002). O documentário, então, renova incessantemente a ficção no sentido de que o cinema se abre a novas possibilidades, já que o seu modelo baseado em filmar aquilo que é recorrente vem se esgotando.

O documentário se sustenta, então, nesse impasse de apresentar aquilo que é proibido ou irrepresentável, segundo Lyotard, procurando encontrar o método 
adequado de filmar a realidade ou, ao contrário, de partir para filmar o outro, descobrindo de fato a essência do cinema que nada mais é do que a "comédia humana”, o "teatro da vida", o "homem sem qualidades". Em suma, uma imagem cuja forma restaura nossa relação com o mundo, explorando suas contradições.

Nesse sentido, podemos dizer que o real resiste dentro de um ciclo imaginário de destruição e (re)construção, onde o documentário encontra a sua potência e autonomia na diversidade de formatos e escrituras.

É dessa forma que podemos dizer que Morin muito contribuiu para a compreensão do cinema contemporâneo; mesmo que a sua influência não seja diretamente atribuída pelos teóricos de cinema, percebemos o eco do seu pensamento, por exemplo, nas idéias desenvolvidas por Christian Metz em relação ao significado imaginário da narrativa fílmica ou no que diz respeito à valorização da subjetividade em relação à função simbólica do filme como expressão das singularidades do vivido, tema encontrado na obra de Deleuze e Aumont.

A discussão em torno da representação e de seus diferentes caminhos reflexivos, levou-nos a compreender o cinema como fenômeno de percepção social. Hoje, o olhar do pesquisador não se fixa somente na "natureza" do filme e na relação direta que esse entretém com fenômenos específicos, sobretudo com a literatura, mas na apreensão da complexidade do cinema a partir de dois vieses que interagem entre si: um, de valor pragmático, que entende a organização da produção cinematográfica como resultado do meio sociocultural no qual ele se insere, assim como expressão artística autônoma; e outro que compreende o cinema como uma técnica de reprodução cujos desdobramentos e avanços definiram um tipo de experiência constituída através de processos subjetivos.

Nesse sentido, o interesse pelo conteúdo do filme persiste como expressão do cotidiano através da representação dos seus mitos e símbolos, ou como produto do imaginário. O cinema revela-se, então, como um instrumento que nos permite olhar o mundo e cuja originalidade se deve à fusão no espectador-realizador do real e do imaginário através de uma complexa complementaridade onde um não saberia excluir o outro. Podemos dizer, assim, que o cinema, na atualidade, é um suporte 
técnico que pode fazer diferentes tipos de discursos como jornalismo, propaganda, pedagogia, mas também arte.

O cinema pressupõe, assim, uma experiência subjetiva, difícil de ser apreendida e indefinível ou, como diz Godard "nem arte, nem técnica, um mistério"(GODARD, 1998, p.p.182). Essa idéia de Godard carrega um duplo sentido, o da arte-técnica, ou seja, o cinema transcenderia a noção de arte a partir do fato de sacralizar o gesto do homem, dando ênfase à idéia de comunidade humana e transcenderia também a noção da técnica como maneira específica de dar instrumentos ao sensível. Seria aí, portanto, que reside o "mistério" do cinema no sentido que prescinde de imagens animadas e da sensibilidade do pensamento humano.

Esse aspecto pode ser compreendido através daquilo que Alain Badiou definiu como a "poética do cinema"(BADIOU, 1998, p.124), ou seja, é no movimento que o filme se torna o lugar onde encontra o sensível. Dessa forma, podemos dizer que a especificidade do cinema se baseia em nos dar a ilusão de traçar os movimentos do pensamento, ou de nos induzir a operar sobre eles e a partir deles.

As teorias do cinema atribuem ao seu objeto uma especificidade em relação às outras artes devido à sua estrutura complexa baseada em uma construção lingüística específica e desenvolvendo-se dentro de um espaço comunicacional relacionado à cultura e ao pensamento em movimento. Portanto, o cinema tem uma existência e uma vida própria. Segundo Jacques Rancière, "o cinema aciona o dispositivo de nossa psichè e de nossa physis, essa mesma que a ciência física moderna reconhece. $\mathrm{O}$ olho da máquina transcreve diretamente os movimentos do pensamento"(RANCIÈRE, 1998, p.51), ou seja, a mecânica da técnica encontra a energia do espírito. O "mistério do cinema", para ficarmos com a expressão empregada por Godard e citada anteriormente, se basearia, então, na abolição da oposição entre o mundo exterior e o mundo interior, o espírito e o corpo, o sujeito e o objeto, o conhecimento científico e o sentimento despertado. Essa operação de junção pode qualificar a estética cinematográfica.

Assim, a especificidade do cinema como manifestação artística deve-se à capacidade subjetiva de mostrar uma realidade e, hoje em dia, o cinema se renova 
como arte promovendo a interação entre a fala e a imagem, o gênero e o tema do filme, seus personagens e as suas situações-tipo, as formas e os modos de expressão ligados aos gêneros, a "realidade" e a ficção. Essa reflexão sobre o cinema diz respeito a uma recusa de uma reprodução mecânica da realidade em favor de uma reprodução que é da ordem do imaginário, onde o "estoque de imagens"3 constitui um capital fundamental para compreender as relações culturais internas de uma sociedade específica. A imagem cinematográfica deve ser apreendida, então, na sua especificidade, na sua capacidade inventiva, no seu poder de sugestão e de surpresa.

O cinema no início dos anos 90, teve a sua morte anunciada nos quatro cantos do mundo; nesse sentido, para ilustrar a dimensão desse questionamento, em Paris, em março de 1995, foi organizado um colóquio com diretores, produtores, críticos e intelectuais originários de várias partes do mundo, intitulado "Le cinéma vers le deuxième siècle”, onde a grande questão era saber que tipo de espetáculo continuaria a ser feito no meio das grandes transformações por que passava o cinema naquela época. Apesar das interrogações e das grandes mutações, o cinema conseguiu se renovar como atividade simbólica, sustentando a sua existência na diversificação apreendida através da televisão e do vídeo.

O cinema continua sobrevivendo como arte, orientado por três lógicas: estética, representativa e artística. A primeira dá forma à percepção do sensível em comum, a segunda nos remete aos códigos de interação entre os gêneros, os afetos e as expressões, e aos comportamentos sociais, e a terceira lógica faz a junção entre as duas outras (estética e representativa) no sentido de que ela "ficciona" as formas do visível e do sensível de uma sociedade específica. Dessa forma, a mise en scène nunca é pura, pois está sempre em contradição com o valor estético que ela persegue na medida em que considera as emoções do diretor, sua imaginação, seu meio, seu desejo em atingir o público e os meios técnico-econômicos que são colocados à sua disposição. Nesse sentido, o cinema passa, através dos filmes, todos esses elementos em constante mutação, ou seja, a sua atual pluralidade, dando conta dessas mudanças, absorvendo-as e permitindo vê-las em diferentes suportes de imagens.

\footnotetext{
3 Referência à idéia de "Museu Imaginário" de André Malraux, onde cada sujeito através das imagens que o constitui criaria o seu próprio estoque imagético, assim, construindo o seu imaginário.
} 
Assim, através da experiência que consiste em ver filmes em diferentes suportes e desfrutar sentimentos que dividimos com os outros, é que podemos apreender a complexidade do cinema, onde o filme conta a essência dessa complexidade; na atualidade, é o documentário que encarna essa complexidade ao reconstruir o real e dando um novo sentido a idéia de representação, provocando polêmicas, atitudes e fazendo com que haja cada vez mais um amplo diálogo com o filme de ficção.

\section{Referências}

AUMONT, J. Esthétique du film. Paris: Nathan, 1999.

AUMONT, J; MARIE, M. L'analyse des films. Paris: Nathan, 1988.

ARNHEIM, R. Le cinéma est un art. Paris: L'Arche, 1989.

BARTHES, R. L'obvie et l'obtus. Paris: Seuil, 1982.

BAZIN, A. Qu'est-ce que le cinema? Paris: Cerf, 1993.

BADIOU, A. Petit manuel d'inesthétique. Paris: Seuil, 1998.

BURDEAU, Emmanuel. La bonne Nouvelle, in: Cahiers du Cinéma. Paris, $n^{\circ} 594$, 2004.

CASETTI, F. Les théories du cinéma depuis 1945. Paris: Nathan, 1999.

DELEUZE, G. L'image-temps. Paris: Minuit, 1985.

GODARD, J-L. Histoire(s) du cinema, tomo 2. Paris: Gallimard-Gaumont, 1998.

KRACAUER, S. De Caligari à Hitler. Lausanne: L'Age d'Homme, 1973.

LYOTARD, J-F. O acinema, in: Teoria Contemporânea do Cinema. São Paulo: Senac, 2005.

METZ, Christian. A Significação no Cinema. São Paulo: Perspectiva, 1972.

MALRAUX, André. Le Musée Imaginaire. Paris: Folio, 1998.

MORIN, E. O Cinema Ou O Homem Imaginário. Lisboa: Moraes, 1970.

RANCIERE, J. L'historicité du cinema, in: De l'histoire au cinéma. Paris: Complexe, 1998. 